\title{
The Ocular-centric Obsession of Contemporary Societies
}

\author{
Mustapha El Moussaoui \\ Departamento de Composición Arquitectónica, Escuela Técnica Superior de Arquitectura, Universitat Politecnica de Valencia, Spain
}

Received July 8, 2020; Revised November 24, 2020; Accepted December 6, 2020

\section{Cite This Paper in the following Citation Styles}

(a): [1] Mustapha El Moussaoui, "The Ocular-centric Obsession of Contemporary Societies," Civil Engineering and Architecture, Vol. 8, No. 6, pp. 1290 - 1295, 2020. DOI: 10.13189/cea.2020.080613.

(b): Mustapha El Moussaoui (2020). The Ocular-centric Obsession of Contemporary Societies. Civil Engineering and Architecture, 8(6), 1290 - 1295. DOI: 10.13189/cea.2020.080613.

Copyright $\mathrm{C} 2020$ by authors, all rights reserved. Authors agree that this article remains permanently open access under the terms of the Creative Commons Attribution License 4.0 International License

\begin{abstract}
Architecture has significantly transformed in the last century with the development of modern technologies. Since the advent of the industrial age and the advancement of technological tools, architecture has developed, assuming diverse forms, while shaping humanity's immediate built environment. These advances didn't only shape our built environment but also changed our inherited culture. With the easy accessibility to more amenities, our reliability on extensions increased. Moreover, while corporations sought to increase more revenues from profitable products, new strategies were developed to attract more customers. These strategies were established on ocular pleasing products for more desirability. Such systems were not only implemented on micro appliances, but were also reflected on our built environment and urban planning. This paper highlights how societies became obsessed with ocularcentric products. However, it indicates how, in the past century, the visual sense became more dominant over the rest of the senses. This dominance has not only prevailed through literature, architecture, and art, but also ocularcentrism, advocating architects, stakeholders, and planners to prioritize aesthetically pleasing products over the social needs of residents. This paper highlights the ocularcentric phenomenon of societies by providing real-life examples of architecture that act as a repellent to a specific social class, in which it contradicts the sacred role of architecture as an answer to our existential thrownness.
\end{abstract}

Keywords Architecture, Ocularcentrism, Modernity, Designers, Society

\section{Introduction}

Architecture, in its contemporary form, has significantly shifted from what it really had to be to what it became. More recently, people started caring more about the external factor rather than the real within aspect, whether it is on a micro or macro scale. This contemporary social concern for more pleasing products was not the birth of the moment, but rather, it was a sequential evolution of both industries and social adequacy. With the dawn of the industrial age and through the progression of technological tools, architecture has evolved, assuming different forms while shaping humanity's immediate built environment and its culture. Subsequently, architecture shifted from a tranquil of our existential throwness ${ }^{l}$ to a form of ocular pleasing aesthetic designs. In "The Eyes of the Skin", Juhani Pallasmaa, a renowned architect and a theorist, has vehemently stated that appreciation of architecture involves all the five human senses. Whereas it is essential to have a visually appealing architectural structure, it is equally important to walk around the building, smell the air inside, hear the sounds inside, touch its surfaces and possibly taste the walls and floors. Moreover, to experience architecture fully, one has to involve the whole body.

Consequently, as architecture is the integration between

\footnotetext{
${ }^{1}$ Throwness or 'Geoworfenheit', is a concept introduced by the German philosopher, Martin Heidegger, that demonstrates how we found ourselves on earth to face our sufferings, sorrows, and frustrations that are born due to the unchosen social conventions, politics, kindship and dutie.
} 
our social concerns, to the overall culture that displays architecture, architecture must serve as an answer to both, our social and existential concerns. However, our modern society became more obsessed with ocular centric traditions.

This paper highlights how some design decisions are taken based on ocular attractions at the expense of both our built environment and social construct.

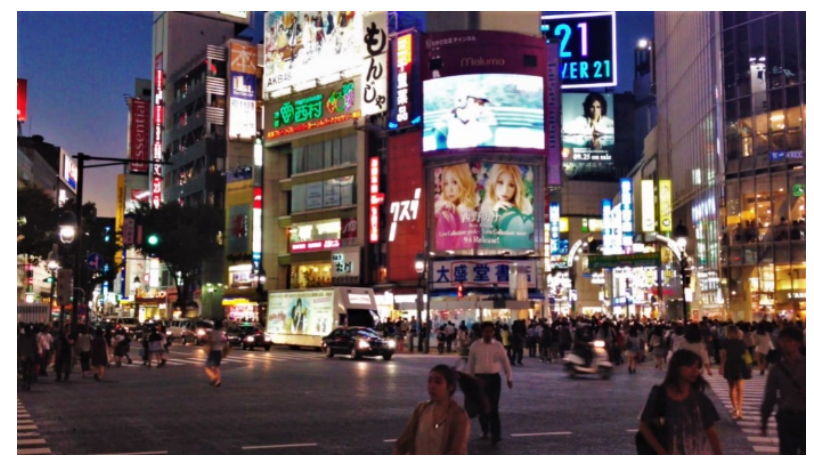

Figure 1. Tokyo. Photo: Author (2014)

\section{Visual Dominance}

According to Bowring (2007), the hegemony of the eye in relation to other body senses has been a characteristic of Western engagement since the Renaissance. Owing to the fact that globalization has colonized space and time, the dominance of the eye has become more pronounced on landscapes throughout the world. Several scholars have written about visual pleasure and ocularcentrism, including David Michael Levin and Martin Jay (Bowring, 2007). These scholars widely discussed the concept of the intersection of ideas of knowledge and those gained from sight. Bowring (2007) states that although the idea of visual hegemony is traced to ancient Greece, it is the emergence of concepts such as perspective and picturesque and viewings based activities such as tourism, museums, and zoos that elevated sight to its hegemonic position. Pallasmaa (2012) confirms that during the Renaissance, the five senses of the body ranked according to their prominence, sense of vision ranks highest while the sense of touch ranks lowest. The Renaissance systems linked vision to light and fire, hearing to air, smell to vapor, taste correlated to water, and touch to earth (Pallasmaa, 2012). The emergence of perspectival representation positioned the eye at the top of the sense's hierarchy. Sight and vision played a crucial role in the perceptual world, as well as in the formation of the concept of self. Modern technological advancement has succeeded in distinguishing the human senses even further. This differentiation is because vision and hearing are given greater preference in social interactions, whereas the other senses are considered sensory remnants assigned private functions and are subjected to suppression through code of culture (Pallasmaa,2012). Kavanagh, D. (2004) adds that contemporary cultures became an ocular centric paradigm because it emphasizes vision-centered interpretation of knowledge, truth, and reality. Moreover, not only sight was the most complex piece of creation that the creator ever created but also, unlike other senses, sight has a theological dimension as it is directly linked to light and the sun. To demonstrate the visual dominance in Western culture, the English language has several visual metaphors (Mateus, 2012). For example, there is the expression take a look, meaning confront an issue or someone. Furthermore, there is the English verb demonstrate that means to show, practically, the verb reveals that there is little difference between language and optics in English speaking nations (Mateus, 2012). In recent years, the emergence of new study fields such as Visual Culture encompassing fields such as photography, computer-mediated interactions, comics, television studies, and videogames confirm the dominance of vision in western societies (Mateus, 2012). On the other hand, this tradition started with ancient Greek philosopher Plato, when he mentioned in his cave allegory that beyond the realm of pure forms, humans are always bound to impressions that are received through the senses, while in specific, using our sight to see the shadows on the walls of the cave.

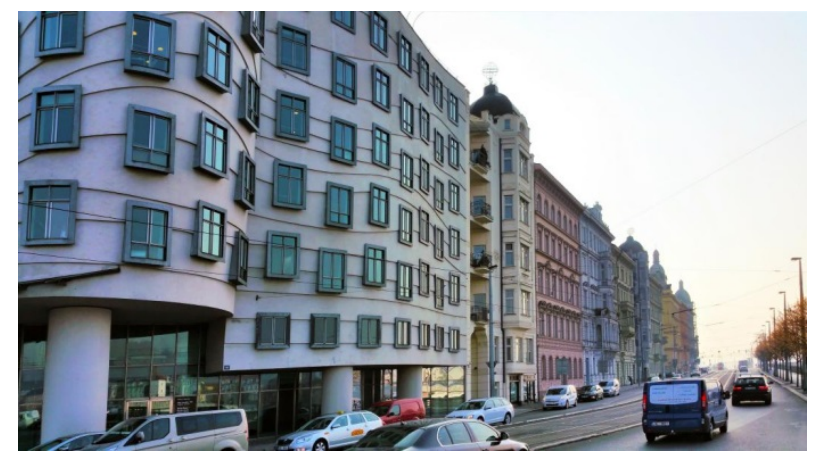

Figure 2. Dancing house in Prague. Photo: Author (2016)

\section{Retinal Architecture and Social Implications}

According to Pallasmaa (1994), modern time architecture is slowly converting into retinal art of the eye. Modern architecture has created a scenario where instead of feeling the world and its architecture from inside, it is felt from outside as spectators viewing an architectural structure from the retina's surface (Pallasmaa, 1994). Rasmussen and Wendt (1962) concur by stating that for centuries painting, sculpture and architecture are "Fine Art."

Modern architecture provides a wide range of possibilities because it manifests differently in its dynamic form than its static variant (Thapa, 2017). Functionality 
and aesthetics are twin considerations when designing a modern building. Practically, architects and designers are seeking to instill new life and energy into structures and products. As a result, designers - with the aid of new technologies - have succeeded in allowing greater experimentation, more personal expression, and vast explorations of design possibilities, which resulted in more significant disparity and the birth of a wide range of commodities, products, and structures. Precisely, a modern expressionist puts more energy into creating a more vibrant and visually interesting architecture (Thapa, 2017).

On the other hand, Levine (2018) argues that modern architects reject traditional design approaches because they believe that they make life better for the masses Many architects believe that modern structures have the power of improving the life of an ordinary person, both spiritually and functionally. H.J Henket asserts that modern architects have a collective responsibility of making life better. However, the opposite is true. The failure of modern architecture to make life comfortable is attributable to the failure to engage all the body sense in architectural designs (Pallasmaa, 1994).

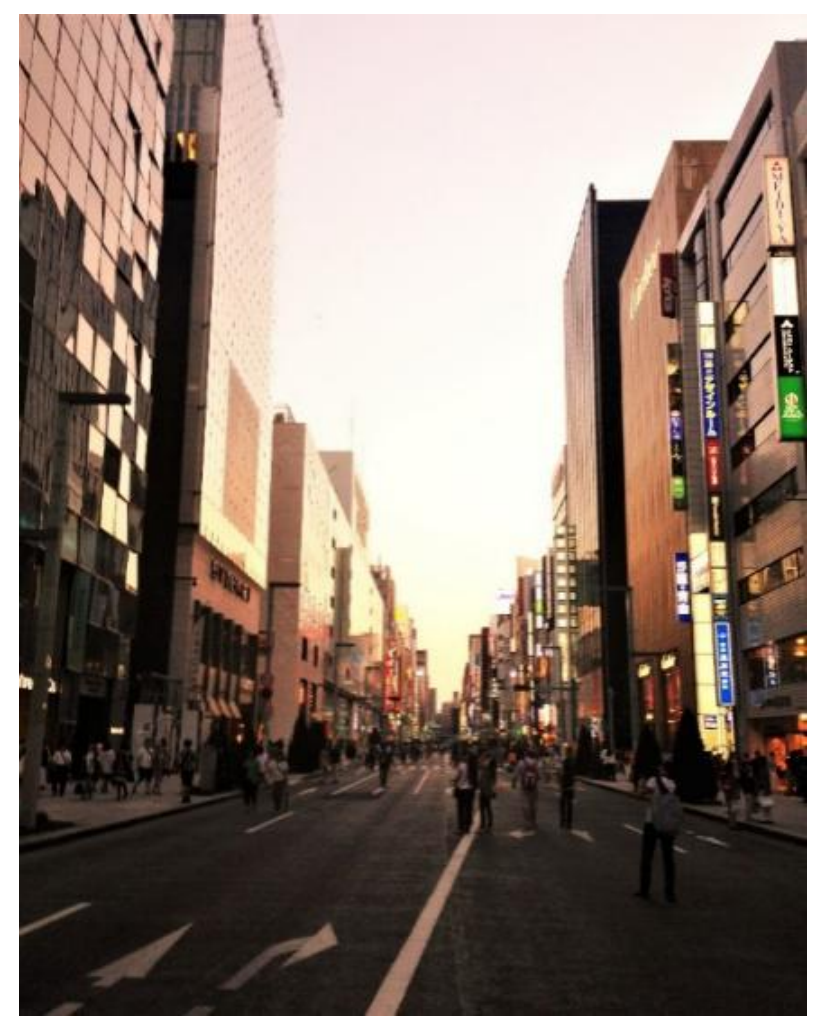

Figure 3. Tokyo. Photo: Author (2014)

On the other hand, architecture had provided a good avenue for exploiting a specific society's ruling ideology through its ability to link city planning and the economy, as it is the showroom and façade of the whole system. For instance, skyscrapers are a proper example that symbolizes the dominance of corporate capitalism in a society (Butler and Watt, 2007). Skyscraper combines several factors that include; economic, technological advancement, and artistic abilities. Practically, the emergence of skyscrapers as architectural structures symbolizes the desire of modern expressionists, capitalists, and to some extent the state, to defeat nature (Butler and Watt, 2007). Through skyscrapers, architects proved that they were able to transcend nature, and all that is natural (Butler and Watt, 2007).

Capitalists, individuals, and governments erected skyscrapers in different parts of the world. However, some structures do not satisfy their functionality or solve social problems, but rather these large sums of money are spent on design and construction for profitable means. According to Bond (2017), urban architects, in many instances, pay no or little attention to the mental effects of their designs on the city's residents or an urban setting. The need to develop a visually appealing design overrides consideration of how the design might influence the people.

During the modernist era, there have been some significant architectural horrors such as the Pruitt-Igoe housing complex located in St Louis, Missouri, and the World Trade Center. Minoru Yamasaki designed the two buildings without involving or considering their impacts on the targeted community (Bond, 2017). After a while, the two buildings became socially dysfunctional and a hotspot for crimes and squalors. Architectural critics theorized that the wide spaces between the two blocks discourage the sense of community, especially after they became hotbeds for crime. In 1972, the two were demolished (Bond, 2017). This demonstrates a lack of priority by the political class to listen to people's needs and act in line with the immediate social need. Likewise, a number of empty skyscrapers characterize London; examples include JG Ballard Story and Waterloo (Parker, 2014). Despite the massive investments pumped into the buildings' design and construction, they are high rises with broken windows that haunt the city. Across London, there have been concerns regarding the emergence of a new shiny city-state that is developing. Old London is on the verge of disappearing beneath a forest of tall buildings, as more buildings are expected to sprout within the Old London territories (Parker, 2014). London's situation is linked to lucrative property prices, in which it makes investing in new constructions an attractive venture. Some capitalists have argued that property owners in underdeveloped sections of London are not doing enough to extract money from the skies (Parker, 2014). According to Parker, rapid advancement in construction technology, lighting, and air conditioning made massive rentable spaces available.

In addition, substantial architectural practices and high-end co-ordinations have made it possible for architecture to assemble large numbers of people and invest in innovative financial services to help investors 
achieve their dreams. Accordingly, demolitions of old buildings are speeding up in different parts of London so that steel can start rising into the sky (Parker, 2014). The structures are out of scale with the human figure. Residents of London argue that the tall buildings turn the street into darkened valleys, and the subject of much gloating is that some of them take up to 20 years before they are occupied (Parker, 2014). This is hypocritical of both capitalists and the government since London is among the global cities that ail from the homelessness of its residents.

According to Andreou (2015), more than 100 homeless people are currently residing in the terminals of Heathrow airport as of the winter of 2015. This is a new record for the city. Official statistics and those produced by non-governmental organizations indicate that homelessness is on the rise in London, and the rise is significantly higher than the national estimates (Andreou, 2015). Despite the high rates of homelessness, the city has adopted strategies of hiding poverty through punishment architecture. There have been erections of anti-homeless spikes in residential complexes in London and other global cities such as Tokyo and New York. The spikes are designed to repulse homeless people from spending their nights in warm neighborhoods with modern architectural technologies (Andreou, 2015). This displays hypocrisy of architects purporting to be designing buildings that solve man's problem and make life more bearable. In fact, architectural designs in public spaces are rejecting the human body (Fig 4).

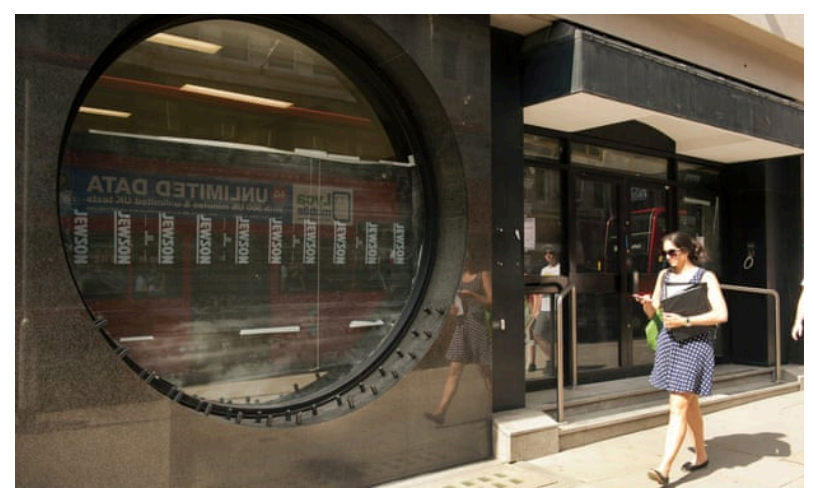

Figure 4. Hostile architecture on the former Coutts Bank, Fleet Street, London. Photograph: Linda Nylind for the Guardian

Additionally, benches in public spaces and exterior of retail stores are designed in a "defensive" or "disciplinary" manner. Metal dividers are placed on public spaces benches to repel homeless people from spending a night in the parks. Furthermore, it is difficult for people who have been dispossessed to rest on benches on bus stops (Fig 5). The emergence of defensive and disciplinary architecture makes it impossible for pregnant women who are experiencing dizzy episodes to rest on their backs. The elderly and the sick are less welcomed into public spaces with spikes and benches with metal dividers (Andreou,
2015)

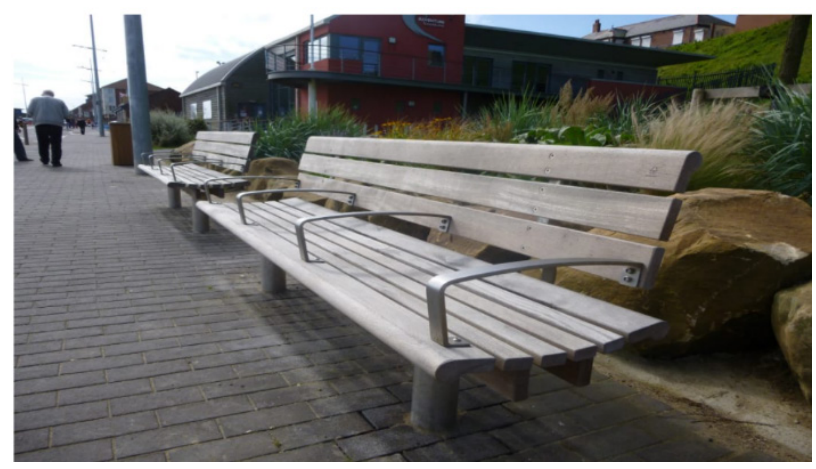

Figure 5. Defensive Architecture. Photo: Katy Wong, CNN Feb 15 2018

By making our cities less accommodative to the human frame, architects are making cities less pleasant to certain social classes - that represents most people - while on the other hand, architecture became more aesthetically pleasing and increasingly hostile to the penurious. The irony is that local authorities, government entities, and municipal councils of different cities spend millions of dollars on aesthetically appealing, defensive, and disciplinary architecture, rather than finding housing solutions for the homeless people. According to Andreou (2015), defensive architecture is revealing when analyzed critically. Nevertheless, repulsive architectural designs are not products of thoughtlessness or accidents but structures that are given due consideration. These structures and designs are thought of by architects, local authorities, developers, and governments. These projects are approved and financed with the sole purpose of excluding and harassing the less fortunate in the society (Andreou,2015). These acts clearly reveal how capitalism and corporate hygiene is considered weightier than human consideration, especially with retail stores and commercial buildings.

It is a clear representation of a clash between necessity and property, private and public. In some instances, it is a clash between the poor and their government. In Guangzhou, government offices are fitted with sprinklers to spray homeless people intermittently, soaking their bodies and their belongings. Long (2017) summarizes the modern picture in the cities by stating that modern humanism $^{2}$ is taming human beings negatively because through humanism, cultural people are grouping themselves in zoos, parks, cities, domesticated spaces, and space stations in such a way that the best group emerges as the dominant group.

\footnotetext{
${ }^{2}$ Humanism is a philosophical and ethical posture that highlights the value and assistance of human beings, individually and collectively, and mostly prefers rationalism and empiricism over acceptance of dogma or superstition.
} 


\section{Design Industry}

In contemporary societies, luxury products and brands are what matter in the end, as they appeal to the eye and attract more consumers. According to Becker, Lee, and Nobre (2018), designed brands in western societies denote specific cultural and social meanings. The brands describe the social positions of their users in society. People who use luxury brands are rich and perceived to belong to higher social groupings. Over the last couple of years, luxurious designed brands have grabbed special attention because of the ethical concerns associated with their production.

Research reveals that throughout the recent economic turbulence, the profit margins for luxury brands in the fashion industry have remained relatively stable (DW, 2019). This phenomenon is attributed to the concept of scopophilia entrenched in our contemporary societies. As stated earlier, visual importance is attached to commodities in contemporary societies that overlooks other aspects of a product linked to a humane aspect. Therefore, designed leather handbags and leather products produced using exploitative and inhumane treatment of both workers and animals are favored in entrenched capitalist environments (Becker, Lee and Nobre, 2018). The companies' record-breaking revenue performances are achievable despite the fact that leather production involves overworking employees, the inhuman killing of animals, environmental pollution, forced and trafficked labor. Following the eye dominance argument, it is inferable that the luxury brands' extrinsic attributes and characteristics are the key driving force for higher sales records despite outcry from environmental, animal, and human rights activists. According to Bowring (2007), visual dominance in western cultures is also linkable to the fear of the "other." Even though the visual appeal is favored, the two-faced nature of visual dominance gives up its problematic feature. This is because, on the one hand, the visual sense is knowledge, and a plethora of English expressions demonstrates that there is a connection between knowledge and sight. On the other hand, pure visual dominance means failure to engage the full body. In architectural terms, it means detachment of architecture from its essential means (Bowring, 2007). It is significant to note that conflict of the establishment of the visual dominance societies does not only influence fashion goods consumerism only but also other industries, including the architecture and design industry, as mentioned earlier.

\section{Conclusion}

In its contemporary form, architecture has significantly shifted from what it really had to be to what it became. Modern societies have expressively transformed towards a retinal art for the eye. This current social concern for more attractive forms was not the confinement of the moment, but rather, it was a successive progression of both industries and social adequacy. With the start of the industrial age and through the progression of technological tools, architecture has evolved, assuming different forms while shaping humanity's immediate environment and culture. Subsequently, architecture shifted from an existential need to a form of ocular pleasing structures. Pallasmaa explains that modern architecture is highly influenced by the fact that sight is the dominant human sense. As a result, most architects strive to design structures that appeal to the eye while ignoring the needs of other human senses. With these ocular shifted structures, architecture has developed to be a source of attraction instead of accommodation, while prioritizing aesthetic concerns rather than social concern. Likewise, the need for visually appealing structures, and business incubators, has pushed for skyscrapers development in different cities around the world, at the expense of having basic shelter for the homeless, refugees, and the deprived. On the other hand, modern architecture has exposed the hypocrisy of governments, which are trusted with the mandate of designing policies that alleviate human suffering, as they are the ones that approve and fund architectural structures that reject a certain social class, at the expense of aesthetically pleasing forms for profitable means. Accordingly, from the prevailed analysis, the dominance of sight in contemporary societies has indeed impaired genuine architectural principles, technologies, and functions. However, the real concern must be protecting our built and natural environment through architects who can connect different scientific fields.

\section{REFERENCES}

[1] Andreou, A., (2015). Anti-homeless spikes: 'Sleeping rough opened my eyes to the city's barbed cruelty. 'Retrieved from https://www.theguardian.com/society/2015/feb/18/defensiv e-architecture-keeps-poverty-undeen-and-makes-us-more-h ostile

[2] Becker, K., Lee, J. W., \& Nobre, H. M. (2018). The Concept of Luxury Brands and the Relationship between Consumer and Luxury Brands. Kip Becker, Jung Wan Lee, Helena M. Nobre/Journal of Asian Finance, Economics and Business, 5(3), 51-63.

[3] Bond, M., (2017). The hidden ways that architecture affects how you feel. Retrieved from https://www.bbc.com/future/a rticle/20170605-the-psychology-behind-your-citys-design

[4] Bowring, J. (2007). Sensory deprivation: globalisation and the phenomenology of landscape architecture. Globalisation and landscape architecture: Issues for education and practice, 81-84. 
[5] Butler, T., \& Watt, P. (2007). Understanding social inequality. London: SAGE Publications.

[6] DW (2019). Luxury: Behind the mirror of high-end fashion DW Documentary (fashion documentary) (Video file). Retrieved from https:/www.youtube.com/watch?v=n7hzo muDEIk

[7] Kavanagh, D. (2004). Ocularcentrism and its others: a framework for metatheoretical analysis. Organization Studies, 25(3), 445-464.

[8] Levine, R. (2018). Modern Architecture \& Ideology: Modernism as a Political Tool in Sweden and the Soviet Union. Momentum, 5(1), 6.

[9] Long, F. (2017). Transhuman Education? Sloterdijk's Reading of Heidegger's Letter on Humanism. Journal of Philosophy of Education, 51(1), 177-192.

[10] Mateus, S. (2012). Social Networks Scopophilic dimensionsocial belonging through spectatorship. Observatorio
$\left(O B S^{*}\right)$.

[11] Pallasmaa, J. (1994). An architecture of the seven senses. Architecture and Urbanism-Tokyo-, 27-38.

[12] Pallasmaa, J. (2005). The eyes ofthe skin. Architecture and the Senses. Chichester.

[13] Parker, M., (2014). Skyscrapers show capitalism at its worst, and its most sublime. Retrieved from https://theconversatio n.com/skyscrapers-show-capitalism-at-its-worst-and-its-mo st-sublime-30223

[14] Rasmussen, S. E., \& Wendt, E. (1962). Experiencing architecture. Cambridge, Mass: M.I.T. Press.

[15] Sharr, Adam, Heidegger for Architects , (London, Taylor \& Francis, Routledge, 2007)

[16] Thapa, R. (2017). Rhythm in Architecture: an Aesthetic Appeal. Journal of the Institute of Engineering, 13(1), 206-214. 